pioneering book of 1961, Simba, in which this painstaking scientist relates his studies of lions in the Nairobi National Park, carried out intermittently through a period of nearly ten years. Schaller's study was a continuous one, occupying almost the whole of three and a quarter years, and although Schaller complains of the inadequacies of his study, caused by its shortness, it is, in its intensity, a study that at last does justice to the supreme predator.

The social structure of a community of lions (such as the 2,000 or so in the ecological unit of the Serengeti) has to be discerned in the setting of a complex system of lion land-tenure. Some lions are resident and their focus is the pride. These lions are territorial but their range overlaps widely with neighbours. Other lions, both male and female, are nomads, but neither category signifies permanent status. Nomads may establish temporary territories and they have transitory contacts with a large number of other lions. Patterns of contact, tolerance, and familiarity emerged from Schaller's study but a question persisted that was profoundly important to the interpretation of behaviour, was not superficially anthropomorphic, and yet was tantalizingly elusive of answer: how many of these lions knew one another?

Fighting amongst lions was common, they often killed one another, and occasionally were cannibals. Territory holders did not always win an engagement with intruders.

The facts that Schaller has assembled on population dynamics and mortality in lions comprise most important new information about large predators. Most striking are the very heavy losses of cubs: $67 \%$ die. Abandonment, violence by adult lions, predation by hyaenas or leopards and starvation are the main causes of their deaths. Altogether the aggressive interactions between lions are seen to be an extremely potent force moulding their behaviour and survival pattern. Yet this aggression has marked survival value, for there are regular seasons and occasional years when lions have great difficulty in catching enough prey and many starve.

Schaller argues convincingly that food is the main factor controlling the lion population, yet he also presents compelling evidence for the importance of territory and adequate space. To read Schaller's findings, however, gives a strong impression that the lions are at too high a density. Many litters are abandoned and juvenile losses are high; the interval between litters is over twice as long as need be physiologically and some lionesses are barren; fatal encounters between adults are common, and so on. Undoubtedly, however, there are many periods when prey are superabundant and more lions could be supported. The reproductive activity of lions is extremely labile and shows fascinating adaptation of physiological response to social and density factors.

Finally there is a wealth of new observation and invaluable statistics about the relation of predator and prey and the lion's hunting methods. In the Serengeti the zebra is the most frequent prey, far out of proportion to its abundance. I could discern no way in which its stripes avert the ultimate disaster of falling victim to the lion.

Facts about other predators, a general discussion of their social systems, and of the dynamics of predation, complete the assembled evidence and make this book a superbly rewarding outcome of the author's years of patient work. Schaller had his own reward in the work itself. In the days and nights of watching he became the familiar of the pride. ... "I had empathy with their problems, I anticipated their future." He, at least, came to know who was who.

Peter JeWeli

\section{Psychology of Industry}

The Social Psychology of Work. By Michael Argyle. Pp. xii +291 . (Allen Lane: London, October 1972.) $£ 2.95$.

Mr ARgyle has set himself the task of producing "a book that is both popular and scholarly". His particular criteria have been that it should be of use to a wide audience; and that all the assertions in it should be based on good evidence, with some of the main sources given.

In large measure he has succeeded. My guess is that the end result will appeal more to thinkers than to doers, but there is no harm in that. We have had an excess of packages of techniques in recent years, and it is refreshing to have someone of lively intellect and wit poking about, turning things over and having a good look, even if it is sometimes done in a rather unmethodical and idiosyncratic way. Bold, questioning managers will probably give $\mathrm{Mr}$ Argyle's book a bigger welcome than will the seekers after management gimmicks; and postgraduates in the behavioural sciences will perhaps think more of it than management students in polytechnics. But to all of them it has information and stimulation to offer. On the usual people-for example, Herzberg, McClelland, Maslow, Vroom -there are level-headed comments, and for once the Tavistock Institute has something useful written about it. Work in primitive societies is given passing but illuminating attention; and so are developments in modern societies (including Yugoslavia, Japan and Israel) which we in Britain do not often hear about.

Sometimes $\mathrm{Mr}$ Argyle says things which make one wonder about his second criterion. For example, he asserts that for many years industrial psychologists concentrated their attention on the performance of manual skills, and that "no interest was taken in the more responsible and highly paid supervisors and managers". It would be more accurate to say that in the early days their attention was largely focused on operating (not merely manual) skills; and to say that their great interest in people in senior positions raised anxiety and was strongly discouraged. It is a pity that $\mathrm{Mr}$ Argyle has given further currency to myths which should by now have perished. C. S. Myers, who founded the National Institute of Industrial Psychology half a century ago (after investing much of his time and money in the Cambridge Psychological Laboratory, of which he became the first director), could have put him right on this. Myers is not mentioned in either his bibliography or his name index. $\mathrm{Mr}$ Argyle might, in a book on the social psychology of work, have given a thought to the fact that half of Myers's Mind and Work, published in 1920, was taken up by chapters on restriction of output, systems of payment, and industrial unrest.

In brief, the book is stimulating to read, but it has shortcomings, not least (despite the observations on the Tavistock Institute and some reference to the National Institute's joint consultation survey, and the work of a few individuals) in its neglect of relevant British work. American authors, with few exceptions, have been equally neglectful; but British authors have no excuse for following their example. I shall certainly recommend the book to postgraduate students (to borrow, not to buy, because its publication price is too high), but with reservations.

AleC RoDger

\section{X-ray Spectrochemistry}

X-Rays, Electrons and Analytical Chemistry: Spectrochemical Analysis with $X$-Rays. By H. A. Liebhafsky, H. G. Pfeiffer, E. H. Winslow and P. D. Zemany. Collaborating editor: Sybil Small Liebhafsky. Pp. xii +566 . (Wiley: New York and London, November 1972.) $£ 10.45$.

THIs book is a significant contribution to applied X-ray analysis as was the authors' 1960 book, X-Ray Absorption and Emission in Analytical Chemistry. The 1972 edition has approximately $50 \%$ new material including a chapter on X-ray diffraction and discussions on energy resolution, mathematical methods for calculating concentration and many good comments on practical solutions to X-ray analytical problems. For several years the senior author has been using the material for a graduate course in X-ray analysis at Texas A and $M$. 